\title{
Modification Strategy of ZSM-5 Zeolite for Enhancing p-Xylene Selectivity in Toluene Disproportionation
}

\author{
SIAMAK SHEHNI, SEYED MOSTAFA TABATABAEE GHOMSHEH* \\ Department of Chemical Engineering, Islamic Azad University, Mahshahr, Iran
}

\begin{abstract}
In this study, modified zeolite was used to improve p-xylene selectivity in toluene disproportionation process. ZSM-5 zeolite was modified by introducing the phosphorus/Germanium loading and vacuum $\mathrm{UV}$ treatment from $\mathrm{He}+\mathrm{O}_{2}$ microwave plasma treatment. Results showed that the ZSM-5 zeolite impregnated with Germanium and phosphorus have high p-xylene selectivity (up to 33 $\%)$. A sharp decrease in the acidity properties was achieved after phosphorus loading. By Germanium loading, selectivity increased but conversion did not change much. Also, the highest p-xylene selectivity (47\%) was obtained by P/Ge ZSM-5 with VUV treatment at the highest WHSV of $85 \mathrm{~h}^{-1}$.
\end{abstract}

Keywords: p-xylene, selectivity, toluene, zeolite

\section{Introduction}

Xylenes are very important materials for various processes like production of resins, plasticizers and synthetic fibers. p-xylene is one of the isomers of xylenes that has the highest market demand [1]. pXylene is mainly an important intermediate in the production of terephthalic acid and dimethyl terephthalate, so these compounds are used to make some polyesters [2,3]. In industry, the xylenes are produced through catalytic reforming of naphtha, pyrolysis gasoline stream in a naphtha steam cracker, transalkylation and through toluene disproportionation process [4,5]. Among all the implemented technologies for producing p-xylene, Toluene disproportionation is promising to become an important process in the chemical industry. Different acidic catalysts are used in the toluene disproportionation process.

In the past, liquid acid catalysts were used for these processes. Despite the effectiveness of these catalysts, their toxicity and corrosiveness limited their uses [6,7]. So far various types of catalysts based on acidic zeolites have been used to catalyze toluene conversion [8]. Among the catalysts, zeolites are crystalline 3D structure of sodium aluminum silicates. They are most promising as the versatile substances for catalysts production in petrochemical chemistry $[9,10]$. other applications are included environmental protection [11,12] and adsorption [13] because of special channel structure, high BET surface area, abundant acid sites and thermal and hydrothermal stability [14].

Recently, there are many studies that have been done in order to enhance the catalytic activity and p-xylene selectivity of zeolites [15-17]. For example, to improvement of p-xylene selectivity, different elements impregnation [18-20] has been proposed. In fact, some acidic sites are deactivated by entering of additives into the channels or openings of the pores, thus preventing the production of undesired isomers by increasing diffusion restrictions.

Furthermore, an interesting approach for acidity modification that is based on zeolite partial dealumination is plasma usage. Using this method, the dispersion of the metal is improved and the catalytic activity of the material is improved [21].

In this paper, the ZSM-5 catalyst was modified by phosphorus/Germanium addition and Vacuum $\mathrm{UV}$ radiation from $\mathrm{He}+\mathrm{O}_{2}$ microwave plasma. These samples are evaluated in p-xylene selectivity and toluene conversion. These modification effects on chemical structure, textural properties and finally catalyst performance were investigated.

*email: mtabagh2005@yahoo.com 


\section{Materials and methods}

\subsection{Preparation of modified ZSM-5 zeolite}

Feedstock and seeding gels are used to synthesis of ZSM-5 (Ratio of silicium to aluminum:16, $5 \mu \mathrm{m}$ crystals). Colloidal silica (Ludox AS-40) (40 wt. \% in $\mathrm{H}_{2} \mathrm{O}$, Sigma Aldrich), sodium Hydroxide (>98\%, Sigma Aldrich), tetrapropylammonium hydroxide (TPAOH) (Sigma Aldrich) and deionized water were used to make the seeding gel. The siding gel was aged at $100^{\circ} \mathrm{C}$ overnight. Sodium aluminate $\left(\mathrm{NaAlO}_{2}\right)$ (Merck), sodium hydroxide $(\mathrm{NaOH})$, colloidal silica and deionised water were used to feedstock preparation. After that the seeding solution was mixed with the feedstock gel and the mixture was placed in autoclave at temperature of $160^{\circ} \mathrm{C}$ for $24 \mathrm{~h}$. After washing, filtrating and drying of the resulting product, the template should be removed. So, solid heating was performed slowly at a rate of $5^{\circ} \mathrm{C} / \mathrm{min}$ to $550^{\circ} \mathrm{C}$ in a furnace. Finally, to generate H-ZSM-5, the calcination of ammonium form of ZSM-5 (temperature: $550^{\circ} \mathrm{C}$, time: $8 \mathrm{~h}$ ) was done. The phosphorus modification was done with $\mathrm{H}_{3} \mathrm{PO}_{4}$ ( 85 wt. $\%$ in $\mathrm{H}_{2} \mathrm{O}$, Merck) wet impregnation. At first, $\mathrm{H}_{3} \mathrm{PO}_{4}$ was vigorously mixed with a mixture of catalyst and water at $160^{\circ} \mathrm{C}$ for $1 \mathrm{~h}$. Then, the drying of samples and calcination were carried out at $120^{\circ} \mathrm{C}$ and $550^{\circ} \mathrm{C}$ respectively. Ammonium hydroxide $\left(\mathrm{NH}_{4} \mathrm{OH}\right.$, Merck) in presence of $\mathrm{H}_{3} \mathrm{PO}_{4}$ was used to control the $p \mathrm{H}$ around 5. After the calcination step, the $\mathrm{P}$ modified catalysts immersed in water bath at $80^{\circ} \mathrm{C}$ for $12 \mathrm{~h}$ and consequently dried at room temperature an overnight. To P/Ge-ZSM-5 preparation, the P-ZSM5 zeolites were immersed in $\mathrm{Ge}\left(\mathrm{NO}_{3}\right)_{2}$ (Merck) solution at $35^{\circ} \mathrm{C}$ for $4 \mathrm{~h}$. The resultant $\mathrm{P} / \mathrm{Ge}$ modified ZSM-5 zeolites were dried at $110^{\circ} \mathrm{C}$, and then calcined at $550^{\circ} \mathrm{C}$ for $4 \mathrm{~h}$.

\subsection{Surface modification of P/Ge ZSM-5 zeolites with Vacuum UV treatment}

At first, the samples were placed into the reactor chamber of the microwave plasma system so that they are located at downstream of the plasma area. Then, the surface of samples was exposed to photons. During plasma treatment, the chamber pressure was kept at 40 to $53 \mathrm{~Pa}$. The gas flow rate of helium and oxygen was controlled by two a MKS type 1171 A mass flow controllers. These controllers were set to $60 \mathrm{sccm}$ and $15 \mathrm{sccm}$ for oxygen and helium, respectively. Standard cubic centimeters per minute ( $\mathrm{sccm}$ ) is a unit of flow measurement indicating cubic centimeters per minute $\left(\mathrm{cm}^{3} / \mathrm{min}\right)$ in standard conditions for temperature and pressure of a given fluid. The vacuum pump was then started to help create vacuum in the system. There are two tubes in this system. One tube (helium gas) was connected to the glass injector tube, helium gas went through the plasma cavity as a gas source. Another tube $\left(\mathrm{O}_{2}\right.$ gas $)$ was connected to the chamber wall to flow over the sample as reactive species. After the system reached to constant pressure, the microwave generator is turned on and plasma is started. After up to two hours of constant plasma monitoring, the plasma was turned off.

\subsection{Catalyst characterization}

The samples were analyzed by these instruments:

-The crystallinity and structure of the samples were analyzed with a DJ-3700 X-ray Diffractometer.

-The textural properties were measured by nitrogen adsorption-desorption measurements on BET isothermal equation at $77 \mathrm{~K}$ using SA-9600 BET Surface Area Analyzer.

-Pyridine FTIR was analyzed by a Thermo iS10 spectrometer.

\section{Results and discussions}

\subsection{Crystallinity of samples}

The XRD spectra of modified and unmodified ZSM-5 catalysts is presented in Figure 1. It is observed that, the framework structure of ZSM-5 doesn't change by modification with P and Ge. the characteristic peaks of MFI type zeolite were observed for all samples at $8^{\circ}, 12.04^{\circ}, 23.22^{\circ}, 24.56^{\circ}$ and $25.23^{\circ}$, which conclude that the ZSM-5 framework has not changed after modification with phosphorus and germanium. Since these elements are well distributed in the catalyst structure, no crystalline phase of them is observed in XRD pattern. It is depicted that, the intensity of the two peaks at $8\left(\begin{array}{lll}0 & 1 & 1\end{array}\right)$ and 23.22 (200) decreased considerably after P impregnation and while adding Germanium, this decrease is not 
significant. In fact, phosphorus penetration into the ZSM-5 channels is lead to a decrease in the intensity of these peaks. during subsequent impregnation by Germanium, it does not enter into the zeolite channels, so a decrease in the intensity of these peaks is negligible. Also, ZSM-5 crystallinity after and before VUV is shown in Figure 1. Like before XRD illustrated that all zeolites were dominated by MFI topology at $2 \theta=8^{\circ}, 12.04^{\circ}, 23.2^{\circ}, 24.56^{\circ}$ and $25.23^{\circ}$. As can be seen, there is a decrease in the intensity of XRD peaks, which indicates a decrease in the crystallinity of the ZSM-5 zeolite after VUV treatment. In fact, VUV treatment has caused some structural changes in the zeolite crystallites. By comparing the patterns of samples, it is evident that there is a relative lower intensity of (002) plane (peak at 12.04) with VUV treatment of sample, which indicates the reducing percentage of $\{0001\}$ facets. Also peak at $23.2^{\circ}(200$ facet) was increased in modified sample. It might be explain by that by VUV radiation from $\mathrm{He}+\mathrm{O}_{2}$ microwave plasma treatment, partial dealumination of zeolite occurred. This treatment changes the zeolite crystallites that their size along the $c$-axis is decreased and their size along the b-axis is increased.

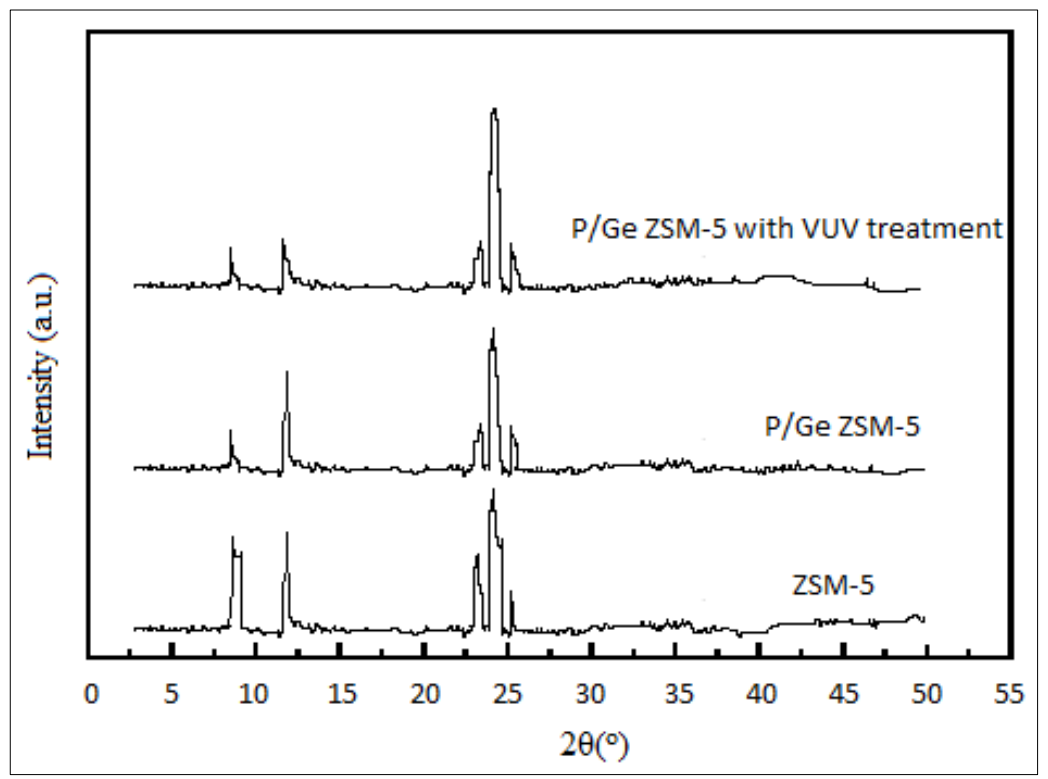

Figure 1. XRD analysis results of zeolites

\subsection{BET analysis}

The results of BET analysis are shown in Table 1. It is clear that with phosphorus modification, the values of these properties are decreased. This phenomenon indicates the entry of phosphorus into the catalyst pores during $\mathrm{P}$ modification as well as coating of the catalyst surface. As can be observed, by subsequent modification of P-ZSM-5 with Ge, these listed properties did not further decrease considerably. This result evidence clearly that the micropores of ZSM-5 do not allow germanium to enter due to its large size, so the species of this element are existence on the external surface of ZSM-5 zeolites which agreements with XRD analysis. Significant findings show a decreasing in BET surface area and an increasing in external surface area when the P/Ge ZSM-5 zeolite is treated by VUV radiation from $\mathrm{He}+\mathrm{O}_{2}$ microwave plasma. VUV treatment unable to change zeolite pores because of it is a surface modification. In fact, the Debye length $(\mu \mathrm{m})$ of this kind of plasma is approximately 1000 times larger than the pore size $(\mathrm{nm})$. Moreover, there is no significant difference of pore volume, pore sizes and particle size between VUV treated and untreated samples.

Table 1. BET analysis results of modified and unmodified catalysts

\begin{tabular}{|c|c|c|c|}
\hline Catalyst & BET surface area, $\left(\mathrm{m}^{2} / \mathrm{g}\right)$ & Pore volume, $\left(\mathrm{cm}^{3} / \mathrm{g}\right)$ & External surface area, $\left(\mathrm{m}^{2} / \mathrm{g}\right)$ \\
\hline ZSM-5 & 318 & 0.151 & 143 \\
\hline P/ZSM-5 & 287 & 1.121 & 112 \\
\hline P/Ge ZSM-5 & 284 & 0.11 & 110 \\
\hline P/Ge ZSM-5 with VUV treatment & 269 & 0.1 & 121 \\
\hline
\end{tabular}




\subsection{Measurement of catalyst acidity}

Pyridine adsorption was utilized to measure the Brönsted and Lewis acid sties. The bands at 3622 $\mathrm{cm}^{-1}$ and $3730 \mathrm{~cm}^{-1}$ correspond to the bridging hydroxyl groups and terminal $\mathrm{SiOH}$ (Figure 2a). The result shows that the intensity of bridging hydroxyls on ZSM-5 declined considerably after Germanium and phosphorus impregnation (Figures $2 \mathrm{~b}$ and 2c). By FT-IR spectroscopy upon pyridine adsorptiondesorption, the Brönsted and Lewis acidities were measured. The relative intensity comparing of the BAS and LAS (in Pyridine adsorption) at $\sim 1547$ and $1435 \mathrm{~cm}^{-1}$ was evidenced indicating the quantity of acidic sites in the ZSM-5 and modified ZSM-5 (Table 2). From the results, it was noted that the intensity of the $\mathrm{OH}^{-}$groups $\left(3622 \mathrm{~cm}^{-1}\right)$ declined considerably by phosphorus incorporation. In fact, phosphorus causes blocking of a large quantity of Brönsted acid sites.

According to Figure 3, the characteristic peaks at 1546 and $1435 \mathrm{~cm}^{-1}$ can be discerned. Also it is clear that ZSM-5 modification with phosphorus decreased drastically both acid sites (Table 2).

By further modification with Ge, the acidity was decreased. Also, modification with Ge is led a decrease in the hydroxyl peaks intensity. In fact, Ge impregnation on the catalyst can cause dealumination of the zeolite and so declines the strong Brönsted acid sites of the zeolite. the peak at $\left(3653 \mathrm{~cm}^{-1}\right)$ allocated to $\mathrm{AlOH}$ groups is proof of this matter. following Ge modification, unlike the Brönsted acid sites the Lewis acid sites were increased. Germanium oxides have acidic properties and the acidic densities could be increased by the Germanium cations. Also a decrease in Brönsted acid sites is due to the interaction of Germanium with the bridging hydroxyl groups of zeolite. By VUV treatment, dealumination of zeolites occurs which in turn increases the number of Lewis and Brönsted acid sites. So, the catalytic activity of zeolites improves.
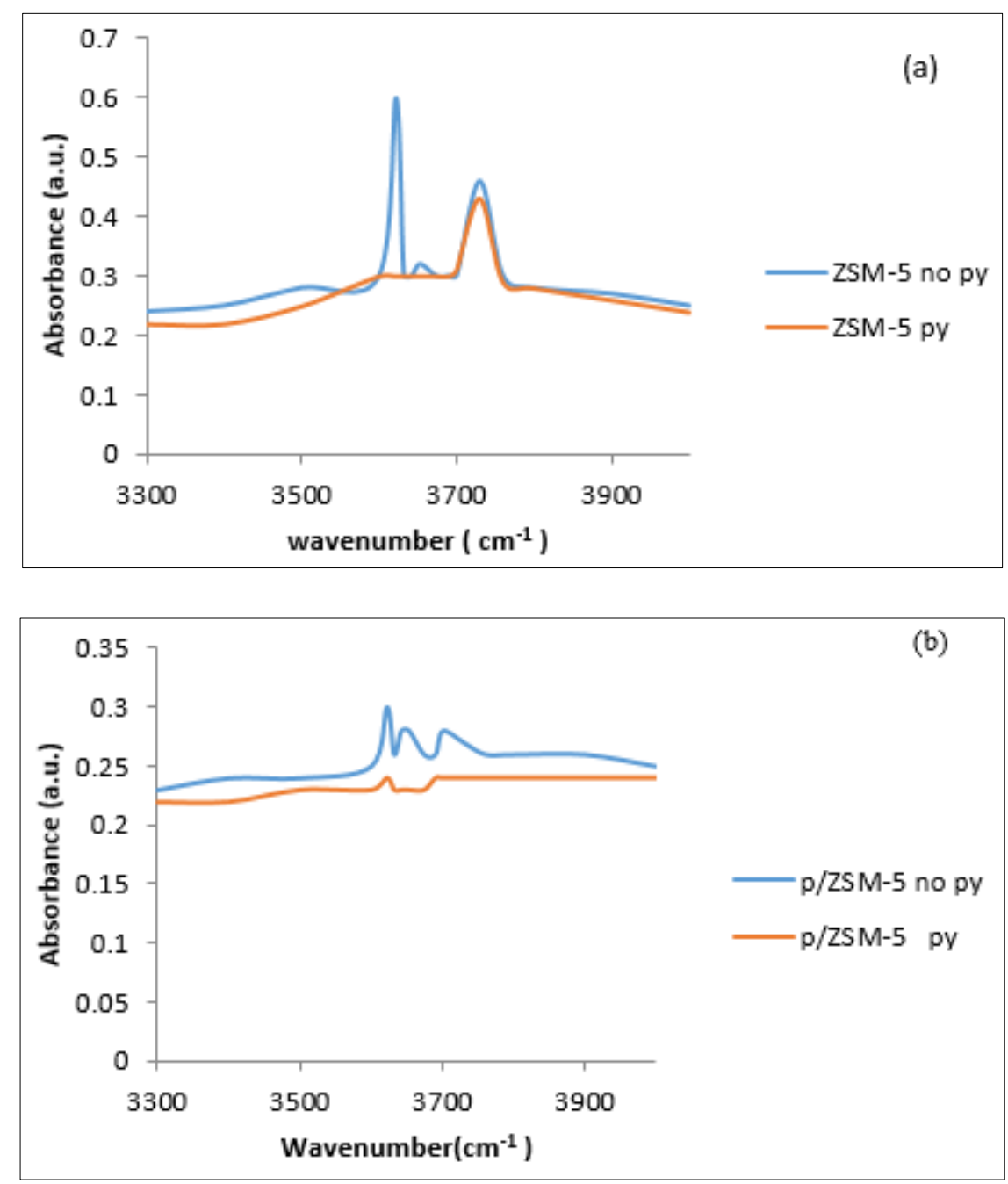


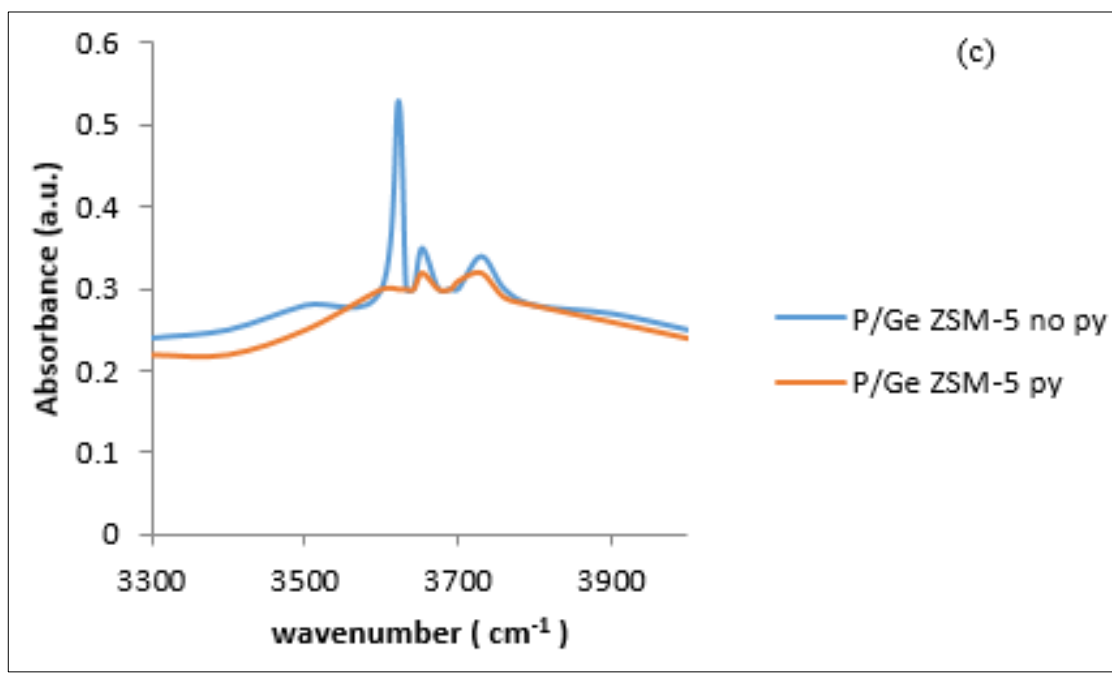

Figure 2. Pyridine and no pyridine FTIR in the Hydroxyl region or ZSM-5 and modified ZSM-5 samples
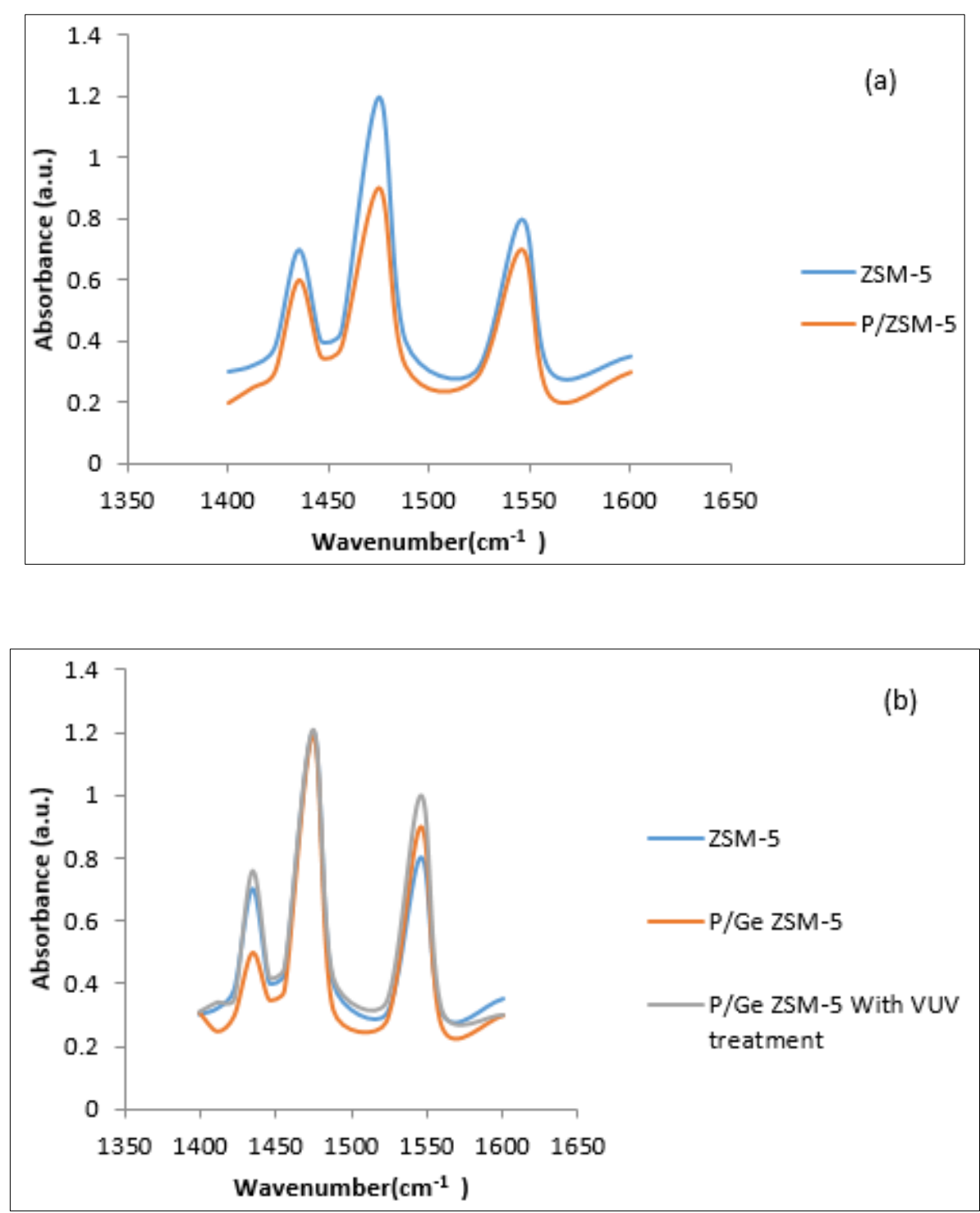

Figure 3. Pyridine FTIR in the BAS and LAS region for ZSM-5 and modified ZSM-5 samples

Table 2. Brönsted andLewis acidity of ZSM-5 and modified ZSM-5 samples 


\begin{tabular}{|c|c|c|}
\hline Catalyst & BAS (mmol/g) & LAS (mmol/g) \\
\hline ZSM-5 & 0.35 & 0.1 \\
\hline P/ZSM-5 & 0.21 & 0.05 \\
\hline P/Ge ZSM-5 & 0.19 & 0.13 \\
\hline P/Ge ZSM-5 with VUV tratment & 0.27 & 0.15 \\
\hline
\end{tabular}

\subsection{Evaluation of catalytic performance}

The reaction runs of toluene disproportionation were conducted at $460{ }^{\circ} \mathrm{C}$, pressure of 10 bars and the WHSV (weight hourly space velocity) of 10 up to $85 \mathrm{~h}^{-1}$. The phosphorus and Germanium impregnating of ZSM-5 was evaluated on catalytic performance of it and was show in Figure 4. Results show that by increasing weight hourly space velocity WHSV $\left(\mathrm{h}^{-1}\right)$, impregnating with phosphorus and Germanium lead to a decline in the conversion of toluene and an increase in the selectivity of p-xylene. This decrease in conversion is attributed to the pore volume, surface area and acidity reduction of zeolites according to FTIR and BET analysis. As the flowrate increases, the catalyst and the feed come into less contact with each other, resulting in less isomerization on the external surface of the catalyst. So the selectivity of p-xylene increases. However, the phosphorus and Germanium modification improved the p-xylene selectivity at increased WHSVs whereas no noticeable change was observed by the unmodified one. Also, catalytic activity of prepared sample with VUV treatment is presented in Figure 4. Since more Lewis and strong Brönsted acid sites are obtained by VUV treatment, so the VUV treated catalyst have a higher toluene conversion than the untreated. Both Ge/P ZSM-5 and VUV treated Ge/P ZSM-5 catalysts showed higher p-xylene selectivity (33\% and 47\%, respectively) than the ZSM-5 value (21\%) at the highest WHSV $\left(85 \mathrm{~h}^{-1}\right)$. By VUV treatment of Ge/P ZSM-5 the best result was obtained for simultaneous increase in selectivity of p-xylene and conversion of toluene.

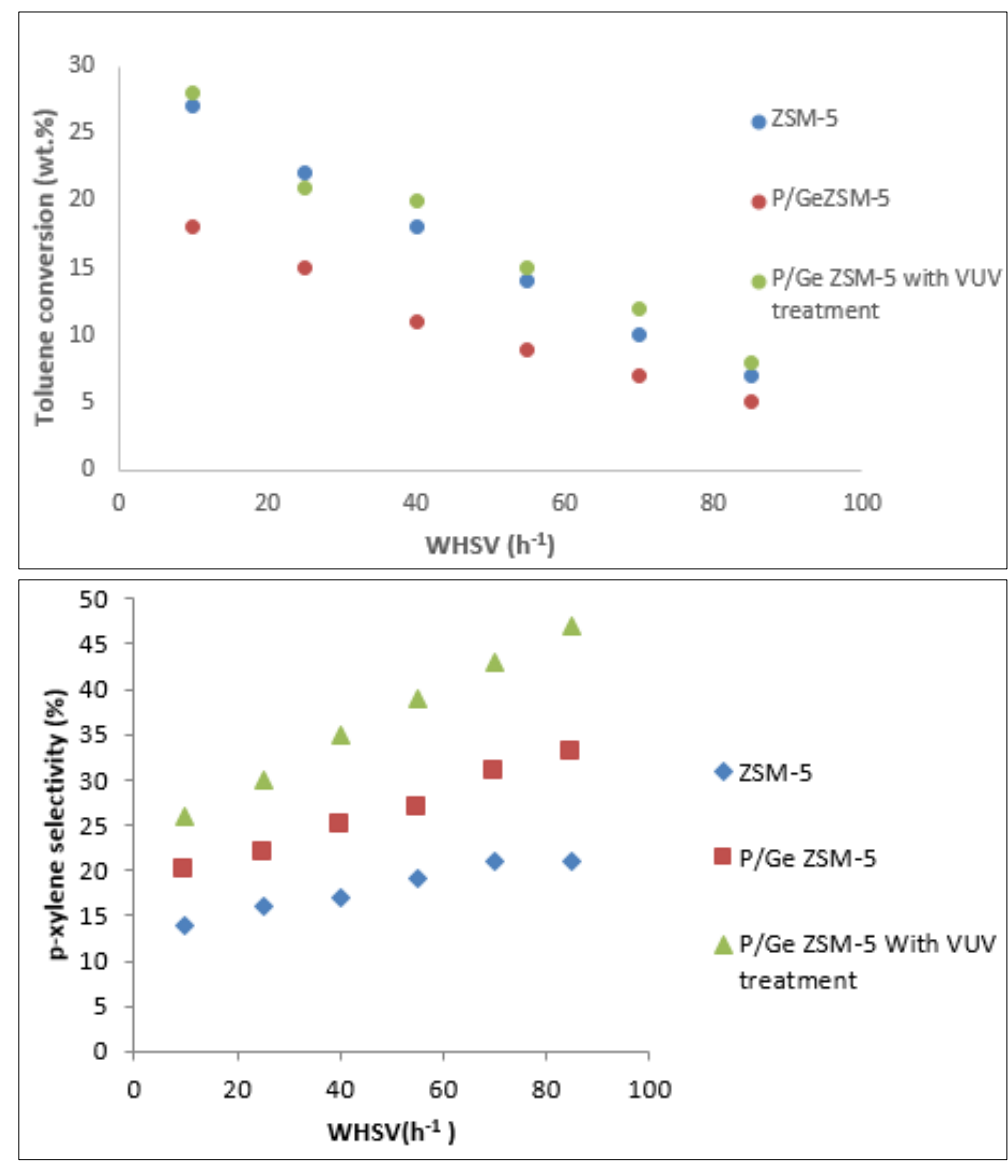

Figure 4. Effect of ZSM-5 modification on toluene conversion and p-xylene selectiv 


\section{Conclusions}

The effects of phosphorus and Germanium impregnation and VUV treatment on ZSM-5 zeolite structure and performance were investigated. Results show that by phosphorus impregnation the quantity of Brönsted and Lewis acid sites considerably decreased. Also, by Ge impregnation the number of Brönsted acid sites was declined and inversely the quantity of Lewis acid sites was increased. Moreover, BET surface area, pore volume and external surface area of ZSM-5 decreased considerably after P modification. This phenomenon indicates the entry of phosphorus into the catalyst pores during $\mathrm{P}$ modification as well as coating of the catalyst surface. By subsequent modification with Ge, the surface and pore volume of zeolites did not further decrease considerably. Generally, the p-xylene selectivity increased reaching 33\% by the modified P/Ge ZSM-5 at the highest WHSV of $85 \mathrm{~h}^{-1}$. By VUV treatment of P/Ge ZSM-5, the p-xylene selectivity was achieved up to $47 \%$.

\section{References}

1.AHN, J., KOLVENBACH. R., AL-KHATTAF, S.S., JENTYSA, A., LERCHER, J.A., Enhancing shape selectivity without loss of activity - novel mesostructured ZSM5 catalysts for methylation of toluene to p-xylene, Chem. Commun., 49, 2013,10584.

2.SCHNEEA, J., QUEZADAA, M., NOROSOA, O., AZZOLINA-JURY, F., ZSM-5 surface modification by plasma for catalytic activity improvement in the gas phase methanol-to-dimethylether reaction, Catal. Today, 337, 2019, 195-200.

3.JI, Y., YANG, H., YAN, W., Strategies to Enhance the Catalytic Performance of ZSM-5 Zeolite in Hydrocarbon Cracking: A Review, Catalysts, 7, 2017, 367.

4. FARAMAWY, S., Selective toluene-methanol alkylation over modified ZSM-5 zeolite catalysts, Pet Sci Technol., 17 ,1999, 249-271.

5.YAO, W., LI, J., FENG, Y., WANG, W., ZHANG, X., CHEN, Q., KOMARNENI, S., WANG, Y., Thermally stable phosphorus and nickel modified ZSM-5 zeolites for catalytic co-pyrolysis of biomass and plastics, $R S C A d v$., 2015, 5, 30485.

6. WANG, Y., CHANG, Y., LIU, M., ZHANG, M., GUE, X., A Facile Strategy to Prepare Shaped ZSM5 Catalysts with Enhanced P-xylene Selectivity and Stability for Toluene Methylation: The E_ect of In Situ Modification by Attapulgite, Molecules, 24, 2019,3462.

7. RASOULI, M., ATASHI, H., MOHEBBI - KALHORI, D., YAGHOBI, N., Bifunctional Pt/Fe-ZSM5 catalyst for xylene isomerization, J Taiwan Inst Chem Eng., 78, 2017, 438-446

8. HAMEDI, N., IRANSHAHI, D., RAHIMPOUR, MR., RAEISSI, S., RAJAEI, H. Development of a detailed reaction network for industrial upgrading of heavy reformates to xylenes using differential evolution technique. J Taiwan Inst Chem Eng., 48, 2015, 56-72

9. SONG, A., MA, J., XU, D., LI, R., Adsorption and Diffusion of Xylene Isomers on Mesoporous Beta Zeolite, Catalysts, 5, 2015, 2098.

10. ALBAHAR, M., CHAOZHOU, L., ZHOLOBENKO, V.L., GARFORTH, A. A., The effect of ZSM5 zeolite crystal size on p-xylene selectivity in toluene disproportionation, Micropor Mesopor Mat, 302 (2020) 110221.

11. ABOUL GHEIT, A. K, ABOUL ENEIN, A., GHONEIM, S.A., HANAFI, S.A., AWADALLAH, A.E., Catalytic p-xylene maximization. Part X: Toluene disproportionation on HF promoted H-ZSM-5 catalysts, Egypt. J. Pet, 21,2012, 119-124.

12.NIU, X., YANG, WANG, K., BAI, Y., DU, Y., CHEN, Y., DONG., M., FAN, W., Selective Formation of P-Xylene by Methanol Aromatization over Phosphorous Modified ZSM-5 Zeolites, Catalysts, 10, 2020, 484.

13. ZHANG, J., QIAN, W., KONG, C. WEI, F., Increasing p-Xylene Selectivity in Making Aromatics from Methanol with a Surface-Modified Zn/P/ZSM-5 Catalyst, ACS Catal., 5, 2015, 2982-2988.

14.ZHENG, S., HEYDENRYCH, H.R., JENTYS, A., LERCHER, J.A., Influence of Surface Modification on the Acid Site Distribution of HZSM-5, J. Phys. Chem. B., 106, 2002, 9552-9558. 
15.JIAN, Z., ZHICHENG, L., LIYUAN, L., YANGDONG, W., HUANXIN, G., WEIMIN, Y., Hierarchical mesoporous ZSM-5 zeolite with increased external surface acid sites and high catalytic performance in o-xylene isomerization, Chinese J Catal, 34, 2013,1429-3.

16.WU T, CHEN S, YUAN G, CAO Y, SU K., Enhanced catalytic performance in butylene cracking by hierarchical surface silicon-rich ZSM-5. Fuel Processing Technology, 2017; 167:162-170.

17.CLOUGH M, POPE J, XIN LIN L, KOMVOKIS V, PAN S, YILMAZ B., Nanoporous materials forge a path forward to enable sustainable growth: Technology advancements in fluid catalytic cracking. Microporous and Mesoporous Materials, 2016; 21: 1-14.

18. KIM, M.S., LEE, D.W., HONG, S.H., HONG, Y.K., LEE, S.H., Oxidation of ammonia to nitrogen over Pt/Fe/ZSM-5 catalyst: influence of catalyst support on the low temperature activity. $J$ Hazard Mater., 237, 2012,153-60.

19.MAVRODINOVA, V., POPOVA, M., Selective p-xylene formation upon toluene disproportionation over MCM-22 and ZSM-5 zeolites modified with indium, Catalysis Communications, 6, 2005, 247-252. 20.SONG,C., GIM, M.Y., LIM,Y.H., KIM, D.H., Enhanced yield of benzene, toluene, and xylene from the co-aromatization of methane and propane over gallium supported on mesoporous ZSM-5 and ZSM-11, Fuel, 251, 2019, 404-412.

21.FARSHADI, M., FALAMAKI, C., Ethylbenzene disproportionation and p-xylene selectivity enhancement in xylene isomerization using high crystallinity desilicated H-ZSM-5, Chin. J. Chem. Eng. 26, 2017, 116-126

Manuscript received: 22.06 .2021 